IFN Working Paper No. 776, 2008

\title{
Venture Capitalists, Asymmetric Information, and Ownership in the Innovation Process
}

Simona Fabrizi, Steffen Lippert, Pehr-Johan Norbäck and Lars Persson 


\title{
Venture Capitalists, Asymmetric Information, and Ownership in the Innovation Process*
}

\author{
Simona Fabrizi ${ }^{\dagger} \quad$ Steffen Lippert ${ }^{\ddagger} \quad$ Pehr-Johan Norbäck ${ }^{\S}$ \\ Lars Persson
}

November 11, 2008

\begin{abstract}
In this paper we construct a model in which entrepreneurial innovations are sold into oligopolistic industries and where adverse selection problems between entrepreneurs, venture capitalists and incumbents are present. We show that as exacerbated development by better-informed venture-backed firms is used as a signal to enhance the sale price of developed innovations, venture capitalists must be sufficiently more efficient in selecting innovative projects than incumbents in order to exist in equilibrium. Otherwise, incumbents undertake early preemptive, acquisitions to prevent the venture-backed firms' signaling-driven investment, despite the risk of buying a bad innovation. We finally show at what point the presence of active venture capitalists increases the incentives for entrepreneurial innovations.

Keywords: venture capitalists, innovation, entrepreneurs, signaling, development, MधAA

JEL classification: C7, D21, D82, G24, L2, M13, O3
\end{abstract}

${ }^{*}$ We are grateful to Marius Schwartz and Tim Worrall for their feedback on an earlier version of this paper. We would also like to thank seminar participants at University of the Basque Country, Queen's University Belfast, Keele University, Massey University, University of Melbourne, University of Otago, University of Waikato, Victoria University of Wellington, as well as participants in the 2007 New Zealand Finance Colloquium, the 2007 Australasian Economic Theory Workshop, the 2007 International Industrial Organization Conference, the 5th International Conference on Logic, Game Theory and Social Choice, the 3rd annual Spain Italy Netherlands Meeting on Game Theory, and the 2007 Econometric Society's Australasian Meeting for their helpful comments. Norbäck and Persson gratefully acknowledge financial support from the Tom Hedelius' and Jan Wallander's Research Foundation. This paper was written within the Gustaf Douglas Research Program on Entrepreneurship. Lippert gratefully acknowledges research funds from the CEPR (EC Contract no. HPRN-CT-2002-00224, CPIM). Fabrizi acknowledges support by the Basque Government, Programa de Formación de Investigadores del Departamento de Educación, Universidades e Investigación, University of the Basque Country (project 9/UPV 00035.321-13560/2001).

${ }^{\dagger}$ Massey University Auckland, Department of Commerce, Private Bag 102 904, North Shore Mail Centre, Auckland, 0745, New Zealand. Email s.fabrizi@massey.ac.nz

${ }^{\ddagger}$ Massey University Auckland, Department of Commerce, Private Bag 102 904, North Shore Mail Centre, Auckland, 0745, New Zealand. Email s.lippert@massey.ac.nz

${ }^{\S}$ Research Institute of Industrial Economics (IFN), Box 55665, SE-102 15 Stockholm, Sweden. Email pehr.johan.norback@ifn.se

TResearch Institute of Industrial Economics (IFN), Box 55665, SE-102 15 Stockholm, Sweden. Phone: +468665 4504. Fax: +468665 4599. Email lars.persson@ifn.se 


\section{Introduction}

Entrepreneurs possessing early stage innovations that need development to be commercially viable in oligopolistic markets have two main options. The entrepreneur may either sell the early stage innovation directly to an incumbent or seek financial support from an independent actor, such as a venture capitalist. Typically there are large informational problems associated with assessing the value of an undeveloped innovation, thus the ability to evaluate it will likely vary between different actors, such as incumbents and venture capitalists. The purpose of this paper is to examine how these information asymmetries determine the ownership and development patterns of innovations that will be used in oligopolistic markets.

To this end we develop a model with the following features: There is a product-market which is served by several incumbent oligopolists. There is also an entrepreneur possessing an early stage innovation that needs development in order to be commercially viable in that market. The entrepreneur cannot personally develop the early stage innovation but instead may sell it to one of the incumbents or, alternatively, seek support from one of several venture capitalists.

We assume that the innovation may be good or bad for development. In particular, we assume that if it is good, investment in its development increases the acquiring firm's product-market profit and decreases the profits of the non-acquiring rivals. On the other hand, if the nature of the innovation is bad, its development has no effect on product-market profits. We assume the nature of the idea to be the entrepreneur's private information.

As the investment in development has an impact on product-market profits only as long as the innovation is good, and as investment in bad ideas is assumed to be costly for a venture-backed firm, the size of the investment in development may serve as a signal ${ }^{1}$ of the innovation's type to potential late-stage acquirers. We assume that after development the venture-backed firm's exit takes place by means of a sale to an incumbent firm. ${ }^{2} 3$

\footnotetext{
${ }^{1}$ Technology journals provide evidence that firms in high-tech industries indeed use technology proxies such as the number of R\&D personnel to signal the value of their firms to investors. See [36] Megginson, Wang, and Chua, (2001) and references to articles in technology journals therein.

${ }^{2}$ For instance, [10] Cochrane (2005) uses data over the period 1987 to June 2000 from the VentureOne database and shows that $20 \%$ of the ventures were acquired, $21 \%$ were IPOs, $9 \%$ went out of business, while $49 \%$ remained private. [12] Cumming and MacIntosh (2003) found similar figures.

${ }^{3}[22]$ Granstrand and Sjölander (1990) and [23] Hall et al. (1990) present evidence, from Sweden and
} 
Finally, we assume that the acquirer and the non-acquiring incumbents compete in the product market.

We first show that when venture-backed firms are better informed they have an incentive to a large investment to signal the high quality of the innovation to be sold to the incumbents, since this increases the sale price of the developed innovation.

We next turn to the issue of whether the incumbents benefit from waiting for the venture-backed firm's signaling. Prima facie, it seems reasonable to believe that the incumbents would prefer to allow a better informed venture capitalist signal the quality of an innovation prior to acquiring it. However, due to the interaction between informational and oligopolistic externalities, this comes at a cost. Indeed, we show that if the venture capitalists' informational advantage is not too large, it is optimal for the incumbents not to wait but rather to use a preemptive acquisition. Key to understanding this result is to see how the signal affects the acquisition price of the developed innovation in an oligopolistic setting. In equilibrium, the acquisition price of the developed innovation is shown to equal an incumbent firm's valuation of obtaining it which, in turn, consists of the difference between the firm's profit if it obtains the developed innovation and its profit if the innovation is obtained by a rival firm. Therefore, the signal through investment in development amplifies the acquisition price by more than the increase in the acquirer's profit; the increase in the acquisition price also reflects the investment's negative impact on the non-acquirer's profit. Thus, acquiring a developed innovation from a venture capitalist may be very costly.

We then show that only if venture-backed firms are sufficiently better informed than the incumbents regarding the prospect of the innovation and if the cost of mimicking a good idea is sufficiently high, the incumbents wait and let a more informed venture capitalist develop an innovation before acquiring it. Consequently, to exist in equilibrium, venture capitalists must be sufficiently more efficient in selecting good ideas than incumbent firms.

We finally show that unless venture capitalists are very inefficient in their signaling, the existence of a venture capital market increases the expected payoff entrepreneurs that receive from engaging in early stage innovative activity. This is true even if the innovation

from the US, respectively, that firms acquire innovative targets to gain access to their technologies. In the biotech industry, [35] Lerner and Merges (1998) note that acquisitions are important for know-how transfers. [38] OECD (2002) argues that established firms often acquire firms to access new technologies. 
is preemptively acquired by an incumbent firm.

Our paper relates to several strands of the economics literature. In the literature that describes the role played by venture capitalists in the innovation process, venture capitalists have been identified to be good at solving moral hazard problems ${ }^{4}$, to be providing managerial value added ${ }^{5}$, as well as to be exploiting strategic product-market effects. ${ }^{6}$ We add to this literature by examining how information asymmetries determine both the ownership of innovations and their development patterns within the innovation industry. By focussing on the implications of the venture capitalists' ability to select good ideas, we relate to recent theoretical papers that study the pre-investment selection and contracting process. ${ }^{7}$ However, the focus of these papers is on the design of the selection process rather than its impact on the post-selection involvement of the venture capitalists which are characterized by signaling and oligopolistic effects which, by contrast, are the key elements of our paper.

The paper is also related to the literature that studies how product-market effects influence the pattern of independent and incumbent-based development of innovations ${ }^{8}$ and which shows that early sales or licensing are more likely when property rights are more secure. Our paper's contribution to this literature is to allow for competitive bidding among the oligopolistic incumbents over the innovation as well as to allow for signaling. This enables us to show that early sales are more likely in cases where the venture capitalists are less efficient in selecting innovation projects relative to incumbents; where those innovations have a high ex-ante potential; and where the cost of mimicking a good innovation is small.

A crucial feature of the models in the signaling literature, ${ }^{9}$ which we share, is that a seller of a good uses some device to signal the quality of the good. We add to this literature by focusing on a productive signal, i.e., a signal that affects the productivity of the asset (good) that is sold post-signaling in the ensuing product-market interaction. ${ }^{10}$

\footnotetext{
${ }^{4}$ See for instance [6] Casamatta (2003), [25] Hellmann (2006), [27] Inderst and Mueller (2004), [30] Kaplan and Strömberg (2001), [32] Keuschnigg and Nielsen (2004), [39] Repullo and Suarez (2004), and [43] Schmidt (2003).

${ }^{5}$ See for instance [29] Kanniainen and Keuschnigg (2003).

${ }^{6}$ See [37] Norbäck and Persson (forthcoming).

${ }^{7}$ See, for example, [7] Casamatta and Haritchabalet (2007), [8] Cestone, Lerner, and White (2007), [11] Cumming and Johan (2008), or [33] Keuschnigg and Nielsen (2006).

${ }^{8}$ See [2] Anton and Yao (1994), [19], [20] Gans and Stern (2000, 2003), and [24] Hellmann (2002).

${ }^{9}$ See, for instance, [40] Riley (2001) for an overview.

${ }^{10} \mathrm{An}$ exemption is [4] Ben-Shahar (2004) who allows for productive signaling in a real estate setting.
} 
Moreover, we add to the signaling literature by endogenously determining whether the ability to signal will be used in equilibrium. In our model, in order to exist in equilibrium, the sender (the venture-backed firm) must be sufficiently better informed (more efficient in the selection of innovations) than the receivers (incumbent firms); otherwise, the receivers (incumbents) will block the signaling through a preemptive acquisition of the early stage innovation.

Finally, by explaining the role that information asymmetries play in the determination of the mode of financing for an innovation, we contribute to the literature regarding how different institutional settings, such as the presence of a venture capital market, may affect the incentives for entrepreneurial innovations in an oligopolistic environment. We thus also add novel insights to the literature on entrepreneurship. ${ }^{1112}$

The model is spelled out in section 2 . In section 3 , we explore how the incentives to develop early stage innovations differ between venture-backed and incumbent firms when asymmetric information problems are present. In section 4, the equilibrium ownership of early stage innovations and incentives for early stage research are discussed. We illustrate our model with a specific example in section 5 and in section 6 we explore the effects of relaxing some of the assumptions made. Section 7 concludes.

\section{The Model}

Consider the model summarized in the timing in figure 1, where an industry is served by a set $\mathcal{I}=\left\{1,2, . ., i, \ldots, N_{I}\right\}$ of ex-ante symmetric oligopolistic incumbents.

In stage 0 , an entrepreneur, denoted $E$, invests in a costly research effort $e$ that could

However, in that paper, no product market effects are present, and no preemptive acquisitions are possible, both of which are crucial to our results.

${ }^{11}$ For overviews, see [1] Acs and Audretsch (2005) and [5] Bianchi and Henrekson (2005). [3] Baumol (2004) stresses the importance of the different roles played by small entrepreneurial firms and large established firms in the innovation process in the US, where small entrepreneurial firms create a large share of breakthrough innovations and large established firms provide more routinized R\&D. To our knowledge very few papers in this literature incorporate oligopolistic effects. An exception is [16] Gabszewicz and Laussel (2007) which proposes a bilateral oligopoly model to study how wealth affects whether individuals choose to become entrepreneurs.

${ }^{12}$ This paper is also pertinent to the literature in the area of patent licensing, where a license is sold at an auction and the potential buyers are competing in a downstream market. See [31] Katz and Shapiro (1986) or, for an overview, [28] Kamien (1992). However, in the patent licensing literature, the size of the investment in the licensed asset affects neither the information set nor the technological set for the acquirer. Instead, in our paper the size of the investment is determined endogenously as a function of both the information asymmetries inherent in the licensing process and the technological implications for the licensee. 


\begin{tabular}{cccll}
0 & 1 & 2 & 3 & 4 \\
\hline \multirow{2}{*}{ Research } & $\begin{array}{l}\text { Auction of } \\
\text { early stage } \\
\text { innovation }\end{array}$ & Development & $\begin{array}{l}\text { Exit of } \\
\text { venture } \\
\text { capitalist }\end{array}$ & $\begin{array}{l}\text { Product } \\
\text { market } \\
\text { competition }\end{array}$
\end{tabular}

Figure 1: The timing of the game.

lead to the creation of a unique asset which we refer to as an early stage innovation. The early stage innovation requires costly additional development for commercial use. We assume that the entrepreneur lacks the financial means to develop the innovation himself. We consider two types of innovations, good and bad ones. We denote an innovation's type with $\theta \in\{g, b\}$, where $g$ stands for good and $b$ for bad. For a good innovation, a costly investment leads to a successful development for commercialized use. A bad one will never be commercially successful, irrespective of the level of investment in its development. We assume that whether the innovation is good or bad is the entrepreneur's private information. It is not verifiable by a court at any point in time and therefore is not contractible. Instead, any investment made in its development is costlessly verifiable.

In stage 1, the entrepreneur may either sell it to one of the incumbents in the industry or, alternatively, seek support from one of the venture capitalists. We assume there to be a set $\mathcal{J}=\left\{1,2, . ., j, . ., N_{J}\right\}$ of symmetric venture capitalists who compete to provide expertise and financial support to the entrepreneur in return for equity holdings in a venture-backed firm founded together with the entrepreneur. We model the decision of whether to sell to an incumbent or to found a venture-backed firm as a first-price sealedbid auction in which the ex-ante symmetric oligopolists and the venture capitalists bid for appropriating the early stage innovation. We assume that venture capitalists are perfectly informed about the innovation's quality, whereas incumbents assign a probability $\lambda \in$ ] 0,1 [ to the event that the innovation is good and $1-\lambda$ to the event that it is bad. ${ }^{13}$ This prior is common knowledge. It is only after obtaining an innovation that an incumbent can inform himself perfectly regarding its nature. We show below that venture capitalists

\footnotetext{
${ }^{13}$ If we assume the incumbents to have received an imperfect signal about the nature of the innovation, where $a \in\left[\frac{1}{2}, 1\right]$ is the probability that the signal is correct and $q$ is the prior probability that an innovation is good, and if we define $\lambda=\frac{a q}{a q+(1-a)(1-q)}$, then $\lambda$ would carry information about the degree of asymmetric information between incumbents and venture capitalists, $a$. If the innovation is good, the higher the $\lambda$, the lower is the asymmetry of information; if the innovation is bad, the higher is the $\lambda$, the higher is the degree of asymmetry of information.
} 
must be sufficiently better informed to be active in equilibrium and thus that our results do not crucially depend on the assumption that venture capitalists are better informed. ${ }^{14}$

If an incumbent firm obtains the innovation in stage 1 , the acquiring firm invests in its development in stage 2. If the entrepreneur obtains financing and support from a venture capitalist in stage 1 , the venture-backed firm then invests in the development of the innovation in stage 2 . We assume the investments to be costlessly verifiable and irreversible. We also assume the development of an innovation to be equally costly for both the incumbents and a venture-backed firm. Venture-backed firms, however, incur an extra cost if they develop a bad innovation. This represents the value of the venture capitalists' reputation, which is potentially lost; or the extra cost incurred for building up a convincing Potemkin village if they invest in bad innovations. In particular, we define the incumbents' development cost function as

$$
C_{i}(k \mid \theta)=C(k),
$$

where $k$ is the chosen level of investment. The venture-backed firms' cost function is defined as

$$
C_{j}(k \mid \theta)= \begin{cases}C(k) & \text { for } \theta=g \\ C(k)+\Delta(k) & \text { for } \theta=b .\end{cases}
$$

Assume these investment cost functions to have the following properties:

Assumption $1 C(0)=\Delta(0)=0, C^{\prime}(k)>0, \Delta^{\prime}(k)>0$.

In stage 3, upon development, the venture-backed firm $j$ exits by selling the developed innovation by means of a perfect information first-price sealed-bid auction, to one of the incumbent firms. We denote the sale price of this late stage, developed, innovation in stage 3 by $S_{3}$, whereas we denote the sale price of the early stage, undeveloped, innovation in stage 1 by $S_{1}$.

Finally, in stage 4, the incumbent firms compete in oligopoly interaction, setting an action $x_{i}$, taking into account the chosen investment level. ${ }^{15}$ This action may be

\footnotetext{
${ }^{14}$ It should be noted that if both venture capitalists and incumbents are not perfectly informed, the analysis, e.g., the auction game in period 1 , becomes much more involved. We expect our main mechanisms also to be present in such an environment. A careful analysis of that case is, however, left to future research.

${ }^{15}$ In the degenerate case where $\lambda=1$, it is shown in [37] Norbäck and Persson (forthcoming) that the acquiring firm will never invest sequentially in equilibrium. As this result would carry over to our model setup, we do not lose generality by assuming that the acquiring oligopolist will not add to the venture capitalist's investment before entering the product-market competition. We gain, however, in the simplicity of our exposition.
} 
considered as (a combination of) setting a price, setting a quantity, and/or engaging in advertising, etc. We assume that, prior to their product-market interaction, the nature of the innovation is revealed to all incumbents. ${ }^{16}$

\section{Incentives to develop}

In this section, we will show how the incentives to develop an innovation differ between venture-backed and incumbent firms. Solving the game backwards, we start with the product-market equilibrium. For the case in which a venture-backed firm has been founded in stage 1 , we then determine the sale price $S_{3}$ in stage 3 and the venture-backed firm's optimal investment decision in stage 2 in a separating perfect Bayesian equilibrium, where venture-backed firms signal the nature of the innovation through their investment choice. For the case of a preemptive early acquisition in stage 1, we instead solve for an incumbent's optimal investment choice in stage 2.

\subsection{Product-market equilibrium}

In the product-market interaction, each firm $i$ seeks to maximize its direct product-market profit $\Pi_{i}\left(x_{i}, \mathbf{x}_{-i}, k \mid \theta\right)$ by choosing an action $x_{i} \in R^{+}$. In addition to its own choice $x_{i}$, its profit also depends on the vector of actions taken by rival incumbent firms, $\mathbf{x}_{-i}$, the amount of development undertaken, $k$, as well as the nature of the project, $\theta$. Assume the existence of a unique Nash equilibrium in actions $\mathbf{x}^{*}(k \mid \theta)$ defined by the first-order conditions

$$
\frac{\partial \prod_{i}}{\partial x_{i}}\left(x_{i}^{*}(k \mid \theta), \mathbf{x}_{-i}^{*}(k \mid \theta), k \mid \theta\right)=0, \forall i \in \mathcal{I},
$$

where $x_{i}^{*}$ is firm $i$ 's equilibrium action and $\mathbf{x}_{-i}^{*}$ the vector of its rivals' equilibrium actions. Using the ex-ante symmetry among incumbents, ex-post there are going to be two types of firms: the acquiring firm, denoted $A$, and the non-acquiring firms, denoted $N$. We denote by $x_{A}^{*}$ the equilibrium action of the acquiring firm and by $\mathbf{x}_{N}^{*}$ the vector of the equilibrium actions of the non-acquiring incumbent firms. Note that the equilibrium actions $x_{A}^{*}$ and $\mathbf{x}_{N}^{*}$ only depend on $k$ and $\theta$. For this reason, we can directly define the equilibrium product-market profits $R_{A}$ of the acquirer and $R_{N}$ of the non-acquirers as

\footnotetext{
${ }^{16}$ Not taking this assumption complicates the analysis without altering the main insights.
} 
functions of $k$ and $\theta:{ }^{17}$

$$
\begin{aligned}
& R_{A}(k \mid \theta) \equiv \Pi_{A}\left(x_{A}^{*}(k \mid \theta), \mathbf{x}_{N}^{*}(k \mid \theta), k \mid \theta\right) ; \\
& R_{N}(k \mid \theta) \equiv \Pi_{N}\left(\mathbf{x}_{N}^{*}(k \mid \theta), x_{A}^{*}(k \mid \theta)\right) .
\end{aligned}
$$

We denote these reduced form product-market profits by $R_{A}$ and $R_{N}$, respectively, as they have revenue character in the investment stage of the game. We assume them to have the following properties:

Assumption 2 The equilibrium product-market profits $R_{A}(k \mid \theta)$ and $R_{N}(k \mid \theta)$ satisfy

1. $R_{A}(0 \mid g)=R_{N}(0 \mid g)=R_{A}(k \mid b)=R_{N}(k \mid b)$;

2. $\frac{d R_{A}(k \mid g)}{d k}>0, \frac{d R_{N}(k \mid g)}{d k}<0, \frac{d R_{A}(k \mid b)}{d k}=\frac{d R_{N}(k \mid b)}{d k}=0$.

This assumption stipulates (1) if a good innovation does not receive investment in its development, or if an innovation is bad for development, this does not affect the product-market profits. It specifies (2) that the equilibrium product-market profit of the acquirer of a good innovation is strictly increasing in the investments in the innovation's development, whereas such investments strictly decrease the rivals' profits; and that the effect of a bad innovation on the product-market is nil, irrespective of the amount of investment in its development. ${ }^{18}$

\subsection{Sale of the developed innovation by the venture-backed firm}

After having solved for the product-market equilibrium, we now turn to stage 3 , the sale of a developed innovation by a venture-backed firm. Note that stage 3 is only reached if in stage 1 there was no preemptive acquisition, i.e., if a venture-backed firm has been established in stage 1. As mentioned, we will solve for a separating perfect Bayesian equilibrium in which a venture-backed firm signals the type of innovation in its possession.

In our model, a perfect Bayesian equilibrium consists of a set of strategies and a belief function, giving the incumbents' common probability assessment that the innovation on

\footnotetext{
${ }^{17}$ To save space, we write the arguments in $R_{N}(k \mid \theta) \equiv \Pi_{N}\left(\mathbf{x}_{N}^{*}(k \mid \theta), x_{A}^{*}(k \mid \theta)\right)$ with a slight abuse of notation. Note that $R_{N}(k \mid \theta)=\Pi_{N}(x_{N}^{*}(k \mid \theta), \underbrace{x_{N}^{*}(k \mid \theta), \ldots ., x_{N}^{*}(k \mid \theta)}_{N_{I}-2}, x_{A}^{*}(k \mid \theta))$.

${ }^{18}$ To keep the exposition simple, we do not formulate this as an assumption on the primitives of the model but use the derivatives of equilibrium product-market profits, $\frac{d R_{A}(k \mid \theta)}{d k}$ and $\frac{d R_{N}(k \mid \theta)}{d k}$, keeping in mind that these summarize the total effects on the product-market profits. This assumption holds, e.g., in the Linear-Quadratic Cournot model which is presented in section 5 but is also compatible with other oligopoly models such as that of [15] Farrell and Shapiro (1990).
} 
sale by a venture-backed firm is good after observing the chosen investment level, such that $(i)$ the venture-backed firm's strategy is optimal given the incumbents' strategies; (ii) the beliefs are derived from the venture-backed firm's strategy using Bayes' rule where possible; and (iii) the incumbents' bids following the observation of the venture-backed firm's chosen investment level constitute a Nash equilibrium in the first-price sealed-bid auction where the probability that the innovation on sale is good is given by the beliefs following this observation. The perfect Bayesian equilibrium is separating if the venturebacked firm's investment choice is different for the two types of innovations.

As in a separating equilibrium the type of the innovation is correctly inferred by the bidding incumbent firms, it is appropriate to model the acquisition process in stage 3 as a perfect information first-price sealed-bid auction with the $N_{I}$ incumbents as the bidders and the venture-backed firm as the seller. After the bids have been announced, the developed innovation is sold to one of the incumbents at the bid price.

In order to solve for the auction, we first consider the incumbents' valuations, $w$, for the developed innovation. For this purpose, define $w(k \mid \theta)=R_{A}(k \mid \theta)-R_{N}(k \mid \theta)$, the first term of which shows the profit for an incumbent firm possessing the innovation and the second term of which shows the profit of an incumbent if the innovation has been obtained by a rival incumbent firm.

Let $k_{j}^{*}(\theta)$ be the venture-backed firm's equilibrium investment choice as a function of the type of innovation in its possession and $S_{3}(k)$ the equilibrium sale price of the developed innovation in stage 3 as a function of the venture-backed firm's investment choice. We can then state the following:

Lemma 1 In any separating perfect Bayesian equilibrium, in stage 3, a good developed innovation is acquired by an incumbent firm at a price equal to a rival incumbent firm's valuation of the developed good innovation, i.e., $S_{3}\left(k_{j}^{*}(g)\right)=w\left(k_{j}^{*}(g) \mid g\right)$; whereas a bad innovation receives an equilibrium price of $S_{3}\left(k_{j}^{*}(b)\right)=w\left(k_{j}^{*}(b) \mid b\right)=0$.

\section{Proof. See Appendix A.}

In the separating equilibrium, the type of the innovation is correctly signaled to the buyers. If the buyers infer from the venture-backed firm's investment decision that the innovation is good, they have a valuation of $w(k \mid g)$, which corresponds to the acquirer's product-market profit less the profit an acquirer would receive from his outside option, i.e., 
from competing as a non-acquirer. The equilibrium action in a perfect information firstprice auction is to bid the second highest bidder's valuation, which - as all incumbents are symmetric - equals the highest bidder's valuation. Thus, the sale price equals the incumbents' valuation $w(k \mid g)$. If they infer that the innovation is bad, the profits of an acquirer and those of a non-acquirer are the same and thus $w(k \mid b)=0$, which is also the equilibrium bid.

\subsection{Development of the innovation and signaling}

Solving the game further backwards, we now turn to stage 2 where we determine the optimal investment in the development of the innovation an acquiring incumbent (subsection 3.3.1) and a venture-backed firm (subsection 3.3.2) would choose.

\subsubsection{The acquiring incumbent's optimal development}

Assume first that an incumbent preemptively acquired the innovation in stage 1. After having acquired the innovation, all assets and documentation from the entrepreneur become his property and the incumbent can perfectly inform himself regarding its nature.

Consider first that the incumbent acquirer $i$ learns that $\theta=b$. As $\frac{d R_{A}(k \mid b)}{d k}=0$, there is nothing to be gained from investing in a bad project and it invests $k_{i}^{*}(b)=0$.

If, on the other hand, the incumbent acquirer learns that $\theta=g$, it chooses an optimal investment level

$$
k_{i}^{*}(g)=\arg \max _{k}\left[R_{A}(k \mid g)-C(k)\right] .
$$

Assume $R_{A}(k \mid g)-C(k)$ to be strictly concave in $k$. Then, $k_{i}^{*}(g)$ satisfies

$$
\frac{d R_{A}\left(k_{i}^{*}(g)\right)}{d k}=C^{\prime}\left(k_{i}^{*}(g)\right) .
$$

Figures 2 and 3 depict this optimality condition in point $A$. From panels $(i)$, it can be seen that in this point, the marginal product-market profit $\frac{d R_{A}(k \mid g)}{d k}$ equals the marginal cost of investment $C^{\prime}(k)$. In panels $(i i)$ it can be seen that $k_{i}^{*}(g)$ maximizes the acquiring incumbent's profit $R_{A}(k \mid g)-C(k)$. We will turn to a description of the other parts of these figures and comment upon them in subsection 3.3.2.

Lemma 2 summarizes our findings.

Lemma 2 The acquiring incumbent's optimal investment in stage 2 is $k_{i}^{*}(b)=0$ and $k_{i}^{*}(g)=\arg \max _{k}\left[R_{A}(k \mid g)-C(k)\right]$. 


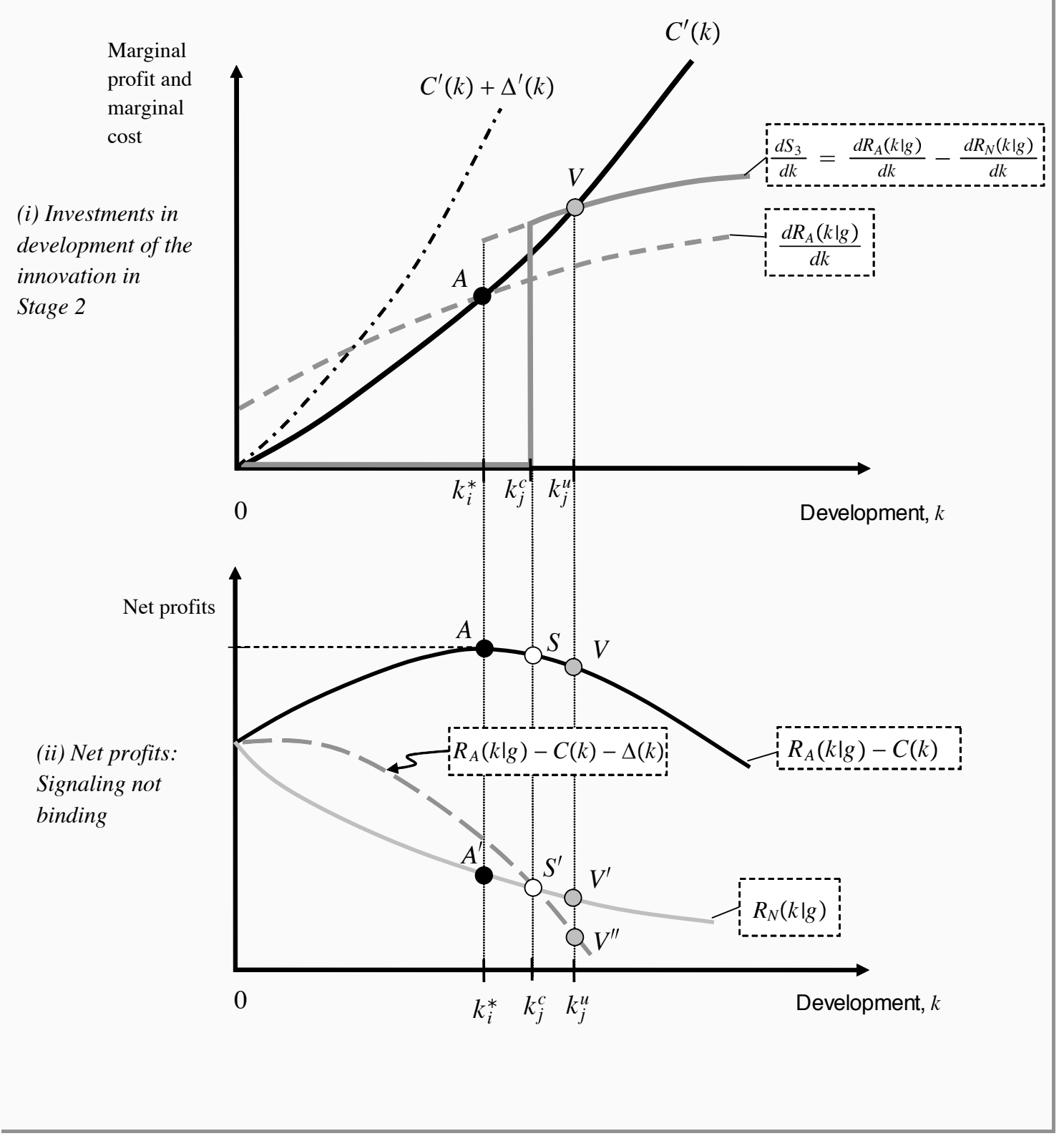

Figure 2: Incentives to develop innovations and net profits when the incentive compatibility constraint is not binding. 


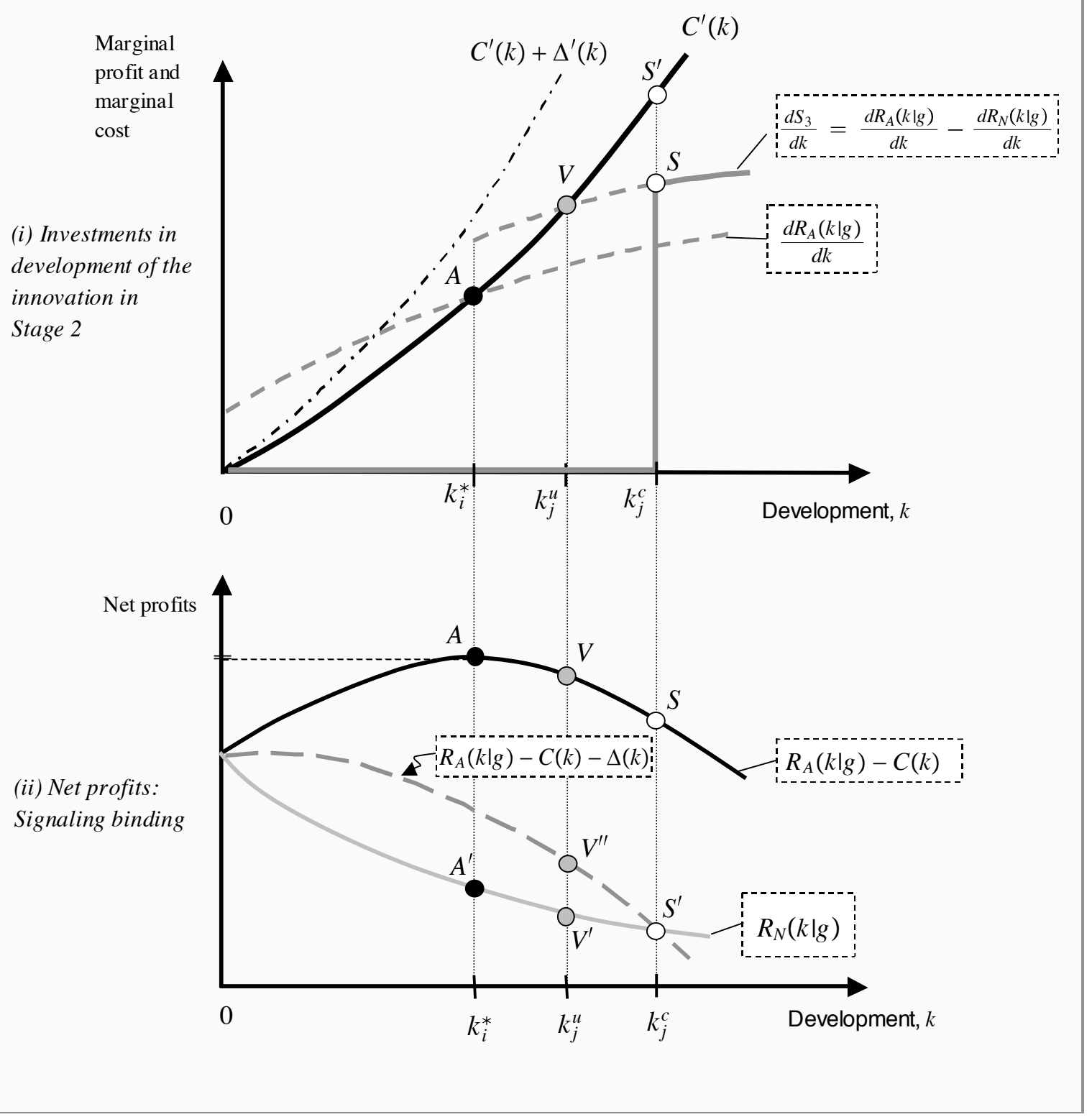

Figure 3: Incentives to develop innovations and net profits when the incentive compatibility constraint is binding. 


\subsubsection{The venture backed firm's optimal development}

Assume now that in stage 1, the entrepreneur teamed up with a venture capitalist to develop the innovation within a venture-backed firm. As the exit of the venture capital investment takes place through a sale in stage 3 , the venture-backed firm chooses its investment level $k_{j}$ such that it maximizes the sale price $S_{3}\left(k_{j}\right)$, derived in Lemma 1 , net of the cost of that investment. As we are solving for a separating equilibrium, we need to determine an optimal investment choice for each type of innovation.

Consider the equilibrium investment level for the venture-backed firm owning a bad innovation. As in a separating equilibrium, the bidding incumbents correctly infer the innovation's type and thus bid so that the venture-backed firm receives a sale price of $S_{3}\left(k_{j}^{*}(b)\right)=0$ (see Lemma 1$)$; an investment $k_{j}>0$ does not increase the innovation's value over that for $k_{j}=0$. Therefore, the following Lemma holds:

Lemma 3 In any separating perfect Bayesian equilibrium, $k_{j}^{*}(b)=0$.

Proof. See appendix B.

Using Lemmas 1 and 3, we can now construct the separating equilibrium. For this purpose, first note that assumption 1 implies that the isoprofit curves of a venture-backed firm possessing a bad innovation and those of one possessing a good innovation cross only once in the $S_{3}-k_{j}$ space, i.e., they fulfill the single-crossing property. Using this property, we can define an incentive compatibility constraint $(I C)$ that, if it holds, ensures that a venture-backed firm possessing a bad innovation would not choose the investment level a firm possessing a good innovation is choosing. Equilibrium investment levels $k_{j}^{*}(g)$ and $k_{j}^{*}(b)$ fulfill this requirement if and only if

$$
S_{3}\left(k_{j}^{*}(g)\right)-C\left(k_{j}^{*}(g)\right)-\Delta\left(k_{j}^{*}(g)\right) \leq S_{3}\left(k_{j}^{*}(b)\right)-C\left(k_{j}^{*}(b)\right)-\Delta\left(k_{j}^{*}(b)\right) .
$$

Using this incentive compatibility constraint and the single-crossing property of the venture-backed firm's isoprofit curves, we can define the minimum investment level needed by a venture-backed firm in order to signal the good type of its innovation to the incumbents. Define this investment level with $k_{j}^{c}(g) .{ }^{19}$ We choose the superscript $c$ as, if this incentive compatibility constraint is binding, it will constrain the venture-backed firm in its investment choice to this minimum investment level.

\footnotetext{
${ }^{19}$ That is, $k_{j}^{c}(g)$ is defined by $S_{3}\left(k_{j}^{c}(g)\right)-C\left(k_{j}^{c}(g)\right)-\Delta\left(k_{j}^{c}(g)\right)=0$.
} 
For a visualization, once more consider figures 2 and 3, in particular panels (ii). In these figures, any investment level larger than or equal to the one in point $S^{\prime}$, in which the dashed $R_{A}(k \mid g)-C(k)-\Delta(k)$ and the grey $R_{N}(k \mid g)$ lines intersect, is incentive compatible, as for $k \geq k_{j}^{c}(g), S_{3}(k)-C(k)-\Delta(k)=R_{A}(k \mid g)-C(k)-\Delta(k)-$ $R_{N}(k \mid g) \leq 0$.

Given the incentive compatibility constraint, one consistent equilibrium belief of the incumbents following an investment $k$ is as follows: Incumbents assign a probability one to the project being bad (and bid zero) if they observe $k<k_{j}^{c}(g)$ and they assign a probability one to the project being good (and bid $w(k \mid g)$ ) if they observe $k \geq k_{j}^{c}(g)$.

Now that we have determined the conditions that $k_{j}^{*}(g)$ must fulfill we can solve for its optimal level. For this purpose, note that investment in a good innovation increases its sale price $S_{3}$ as the incumbents' valuation of a good developed innovation in stage 3, $w(k \mid g)$, is an increasing function of $k$. Therefore, it is possible that, in equilibrium, the incentive compatibility constraint is not binding and the venture-backed firm chooses $k$ in order to solve an unconstrained maximization program. Using Lemma 1, the maximizer of this program, i.e., the unconstrained optimal investment of a venture-backed firm, $k_{j}^{u}(g)$, is given by

$$
\begin{aligned}
k_{j}^{u}(g) & =\arg \max _{k}\left[S_{3}(k \mid g)-C(k)\right] \\
& =\arg \max _{k}\left[R_{A}(k \mid g)-R_{N}(k \mid g)-C(k)\right] .
\end{aligned}
$$

Assuming $R_{A}(k \mid g)-R_{N}(k \mid g)-C(k)$ to be strictly concave in $k, k_{j}^{u}(g)$ satisfies

$$
\frac{d S_{3}\left(k_{j}^{u}(g)\right)}{d k}=\frac{d R_{A}\left(k_{j}^{u}(g)\right)}{d k}-\frac{d R_{N}\left(k_{j}^{u}(g)\right)}{d k}=C^{\prime}\left(k_{j}^{u}(g)\right) .
$$

Once more, consider figures 2 and 3. Panels $(i)$ depict how the unconstrained optimal investment level $k_{j}^{u}(g)$ is derived from the optimality condition $\frac{d S_{3}}{d k}=\frac{d R_{A}}{d k}-\frac{d R_{N}}{d k}=$ $C^{\prime}\left(k_{j}^{u}(g)\right)$. Panels (ii) of these figures then examine whether this unconstrained optimal investment level satisfies the incentive compatibility constraint. It holds for $k_{j}^{u}(g)$ in Figure 2, but not in Figure 3.

If $k_{j}^{u}(g)$ is insufficient to signal the good nature of the innovation, as in figure 3 , then the venture-backed firm needs to invest beyond this level in order to signal. As we assumed $R_{A}(k \mid g)-R_{N}(k \mid g)-C(k)$ to be strictly concave in $k$, a venture-backed firm's profit beyond $k_{j}^{u}(g)$ is strictly decreasing. Therefore a venture-backed firm chooses the 
smallest investment level satisfying incentive compatibility, $k_{j}^{c}(g)$. Lemma 4 summarizes this result.

Lemma 4 In the separating perfect Bayesian equilibrium, $k_{j}^{*}(g)=\max \left\{k_{j}^{c}(g), k_{j}^{u}(g)\right\}$.

While Lemma 3 showed that, in a separating perfect Bayesian equilibrium, a venture capitalist does not develop a bad early stage innovation, Lemma 4 demonstrates that it develops good innovations as if there were no incentive compatibility problem as long as the unconstrained optimally chosen level of development suffices to signal. Good innovations are developed beyond this level in order to signal the good nature of the innovation. It follows from the construction of the incentive compatibility constraint that an additional investment must be made whenever it is not sufficiently costly for a venturebacked firm possessing a bad innovation to mimic one possessing a good innovation. Proposition 1 summarizes our results so far.

Proposition 1 In a separating equilibrium, a venture-backed firm signals

(i) the bad nature of an idea by not investing anything in its interim development;

(iia) the good nature of an idea by investing as it would under full information as long as it is sufficiently costly for a venture-backed firm to mimic the development of a good innovation when it is bad; and

(iib) the good nature of an idea by investing more than it otherwise would under full information.

Note that the optimal investment level of a venture-backed firm, $k_{j}^{*}(g)$, is systematically higher than that of an incumbent firm, $k_{i}^{*}(g)$. There are two reasons for that. The first comes from the product-market interaction of the acquiring and non-acquiring incumbents: If $(I C)$ is not binding, the venture-backed firm takes into account the positive impact of its investment on the profits of the acquirer, $\frac{d R_{A}(k \mid g)}{d k}$, but also the negative impact on the non-acquirers' profits, $\frac{d R_{N}(k \mid g)}{d k}$. The second reason comes from the necessity to signal. If $(I C)$ is binding, the venture-backed firm has to invest beyond $k_{j}^{u}(g)$. Therefore, we can state the following:

Proposition 2 For a good project, the optimal level of development by a venture-backed firm which sells the developed innovation to an incumbent firm exceeds the optimal level of development by the acquiring incumbent firm, i.e., $k_{j}^{*}(g)>k_{i}^{*}(g)$. 
This proposition extends Norbäck and Persson (forthcoming) which states that venturebacked firms would develop innovations to a larger extent than incumbents in order to internalize the strategic product-market effects. In addition to this internalization effect, in our framework, venture-backed firms choose even higher investment levels in order to overcome the additional adverse selection problem.

\section{The equilibrium ownership of early stage innova- tions and incentives for early stage research}

In this section, we use the results obtained for the separating equilibrium in order to derive which parties develop innovations and, therefore, how extensively this development will be pursued in equilibrium. To this end, we will first derive the valuations of both venture capitalists and incumbents, determine their equilibrium bids, and then characterize ownership patterns. We conclude the section by pointing out implications for the incentives to come up with early stage innovations.

\subsection{Equilibrium ownership}

The first step in determining the equilibrium ownership and the acquisition price is to derive the stage 1 valuations. In contrast to stage 3 valuations, which we denoted by $w$, these stage 1 valuations will be denoted by $v$. Note that, as venture capitalists know the nature of the innovation, we need to distinguish between valuations for good and bad early stage innovations.

Consider a venture capitalist's valuation for a bad early stage innovation, which is denoted as $v_{j}(b)$. As investing in a bad innovation does not result in an asset that can be sold at a positive price, ${ }^{20}$ a venture capitalist has a valuation of zero for it, i.e., $v_{j}(b)=0$. Now, consider a venture capitalist's valuation for a good early stage innovation, denoted as $v_{j}(g)$. This is the sale price of the developed innovation in stage 3 , net of the investment costs. From Lemma 1, we have $S_{3}\left(k_{j}^{*}(g)\right)=w\left(k_{j}^{*}(g) \mid g\right)=R_{A}\left(k_{j}^{*}(g) \mid g\right)-R_{N}\left(k_{j}^{*}(g) \mid g\right)$

\footnotetext{
${ }^{20}$ This is true as we are solving for the separating equilibrium. We will discuss this equilibrium choice and, in particular, the reasons why we do not present pooling equilibria in detail in the conclusion.
} 
and thus the venture capitalist's valuation of the entrepreneur's early stage innovation is:

$$
\begin{aligned}
v_{j}(g) & =S_{3}\left(k_{j}^{*}(g)\right)-C\left(k_{j}^{*}(g)\right) \\
& =R_{A}\left(k_{j}^{*}(g) \mid g\right)-R_{N}\left(k_{j}^{*}(g) \mid g\right)-C\left(k_{j}^{*}(g)\right) .
\end{aligned}
$$

In line with our earlier notation, we denote by $v_{j}^{u}(g)$ the venture capitalists' valuation if the venture-backed firm is unconstrained in its choice of $k$, i.e., if its incentive compatibility constraint is not binding. Further, we denote by $v_{j}^{c}(g)$ the venture capitalists' valuaton if the venture-backed firm is constrained in its choice of $k$, i.e., if its incentive compatibility constraint is binding.

Let us turn to the valuation of the incumbents. Denote by $v_{i i}$ the ex-ante expected value for an incumbent firm of acquiring the early stage innovation when it would otherwise be obtained and developed by a rival incumbent:

$$
v_{i i}=\lambda\left[R_{A}\left(k_{i}^{*}(g) \mid g\right)-C\left(k_{i}^{*}(g)\right)-R_{N}\left(k_{i}^{*}(g) \mid g\right)\right] .
$$

This is the difference in the expected net profit of the acquirer,

$$
\lambda\left[R_{A}\left(k_{i}^{*}(g) \mid g\right)-C\left(k_{i}^{*}(g)\right)\right]+(1-\lambda) R_{A}\left(k_{i}^{*}(b) \mid b\right),
$$

and the expected profit of the non-acquirer

$$
\lambda R_{N}\left(k_{i}^{*}(g) \mid g\right)+(1-\lambda) R_{A}\left(k_{i}^{*}(b) \mid b\right)
$$

evaluated at the acquiring incumbent's optimal development levels, $k_{i}^{*}(\theta)$. Note that since $v_{i i}$ is not a function of the level of investment chosen by the venture-backed firm, it is independent of whether the venture-backed firm faces a constrained or an unconstrained maximization problem when it chooses the level of investment in the development of the innovation.

Compare $v_{j}(g)$ with $v_{i i}$. If the venture-backed firm's problem is unconstrained, the investment choice is $k_{j}^{u}(g)$, which maximizes $R_{A}(k \mid g)-C(k)-R_{N A}(k \mid g)$. Therefore, in that case, $v_{j}^{u}(g)$ must exceed $v_{i i}$. This is illustrated in Figures 2 (ii) and 4 (ii). In Figure 2 (ii), $v_{j}^{u}(g)$ is shown as the vertical distance between $V$ and $V^{\prime}$. In addition, the vertical distance between $A$ and $A^{\prime}$ gives $v_{i i}$ for $\lambda=1$. Figure 4 (ii) shows both valuations as functions of $\lambda$. It demonstrates how for any $\lambda>0, v_{i i}<v_{j}^{u}(g)$.

If the venture-backed firm's incentive compatibility constraint holds with equality, a venture-backed firm must invest more in order to signal the type of the innovation to the 


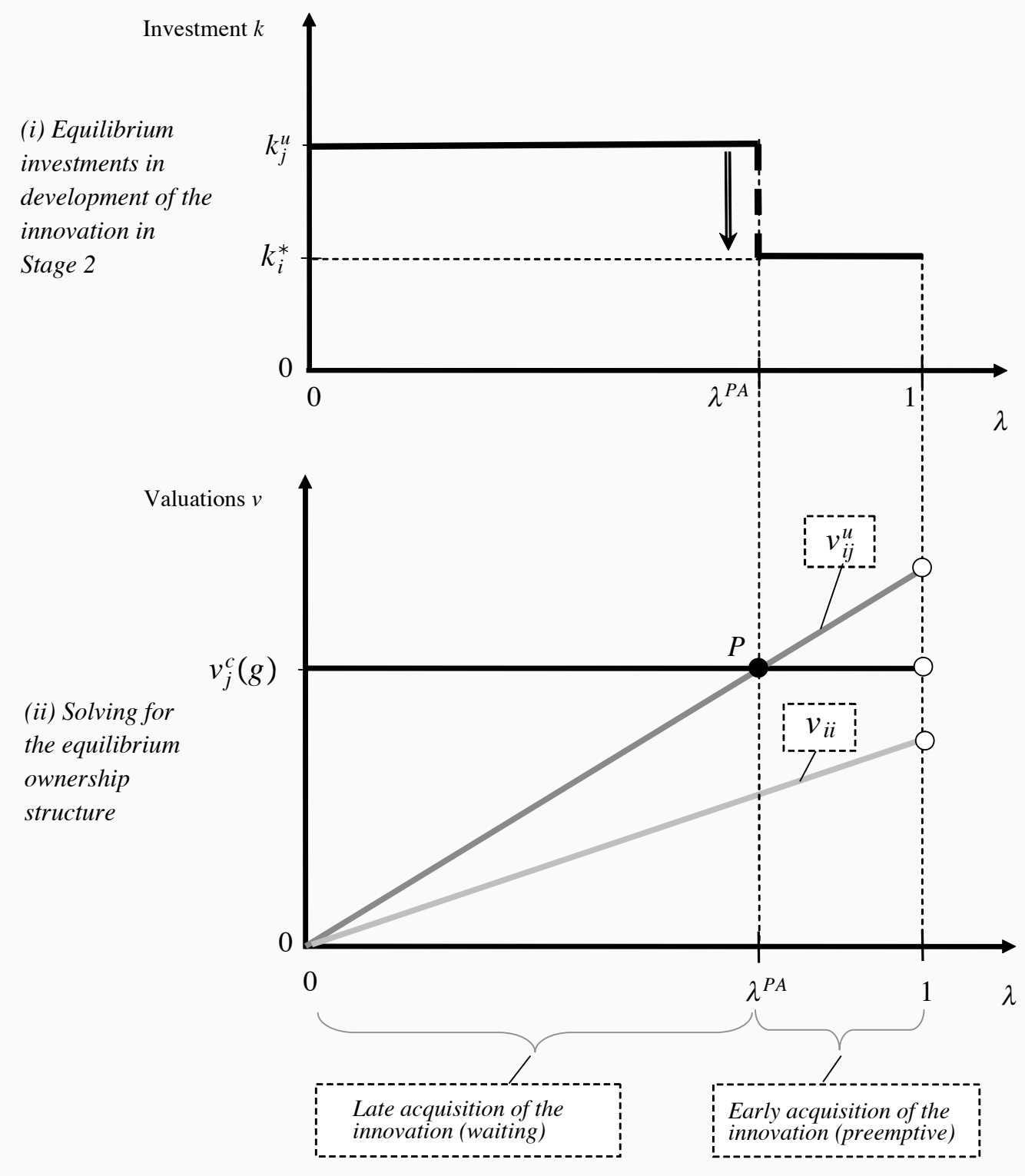

Figure 4: Equilibrium investment and ownership structure with a non-binding incentive compatibility constraint. 
potential acquirers. This is reflected in a lower - constrained maximized - profit from the sale of the developed innovation and thus in a lower valuation for the early stage innovation. Consider panel ( $i i$ ) of figure 3. In this figure, the effect of a binding incentive compatibility constraint on the venture capitalists' valuation is reflected by a smaller distance between $S$ and $S^{\prime}$, as compared to that between $V$ and $V^{\prime}$. Now turn to figure 5 (ii). Here we show the effect of the incentive compatibility constraint by indicating $v_{j}^{c}(g)$, which is smaller than $v_{j}^{u}(g)$.

In the situation where venture-backed firms incur a very small additional cost for developing a bad idea, the minimum investment level needed to signal that the innovation is good, $k_{j}^{c}(g)$, is high. This depresses the venture capitalists' valuation by a large amount. If this situation coincides with a sufficiently high $\lambda$, which results in a relatively high valuation by the incumbents, we may have $v_{j}^{c}(g)<v_{i i}$. Denote the $\lambda$ for which $v_{j}^{c}(g)=v_{i i}$ with $\lambda^{i i}$. In Figure 6 (ii), which depicts this situation, there exists a $\lambda^{i i}$ such that $v_{i i}<v_{j}(g)$ for $\lambda<\lambda^{i i}$ and $v_{i i}>v_{j}(g)$ for $\lambda>\lambda^{i i}$. Lemma 5 summarizes this finding.

Lemma 5 For $\Delta\left(k_{j}^{u}(g)\right)$ sufficiently small, $\left.\exists \lambda^{i i} \in\right] 0,1\left[\right.$, s.t. for $\lambda>\lambda^{i i}, v_{i i}>v_{j}(g)$ and for $\lambda<\lambda^{i i}, v_{i i}<v_{j}(g)$.

Note that the preemptive acquisition of the early stage innovation by another incumbent firm is not the only alternative scenario an incumbent must consider when it is bidding for it. The innovation could be obtained by a venture capitalist. Therefore, we need to take into account the incumbent firms' expected value of obtaining the innovation when it would otherwise be obtained, over-developed, and sold by a venture-backed firm:

$$
v_{i j}=\lambda\left[R_{A}\left(k_{i}^{*}(g) \mid g\right)-C\left(k_{i}^{*}(g)\right)-R_{N}\left(k_{j}^{*}(g) \mid g\right)\right] .
$$

Let us compare this valuation with $v_{i i}$. Recall from Lemma 2 that a venture-backed firm develops a good innovation to a greater extent than an incumbent, i.e., $k_{j}^{*}(g)>$ $k_{i}^{*}(g)$. This implies that a non-acquirer's profit if a venture capitalist obtains a good innovation in stage $1, R_{N}\left(k_{j}^{*}(g) \mid g\right)$, is lower than its profit if a competing incumbent were to acquire it, $R_{N}\left(k_{i}^{*}(g) \mid g\right)$. Therefore, for all $\left.\lambda \in\right] 0,1\left[, v_{i i}<v_{i j}\right.$ : the ex-ante expected value for an incumbent firm $i$ of acquiring the early stage innovation, when it would otherwise be obtained by a rival incumbent, $v_{i i}$, is strictly smaller than its expected 


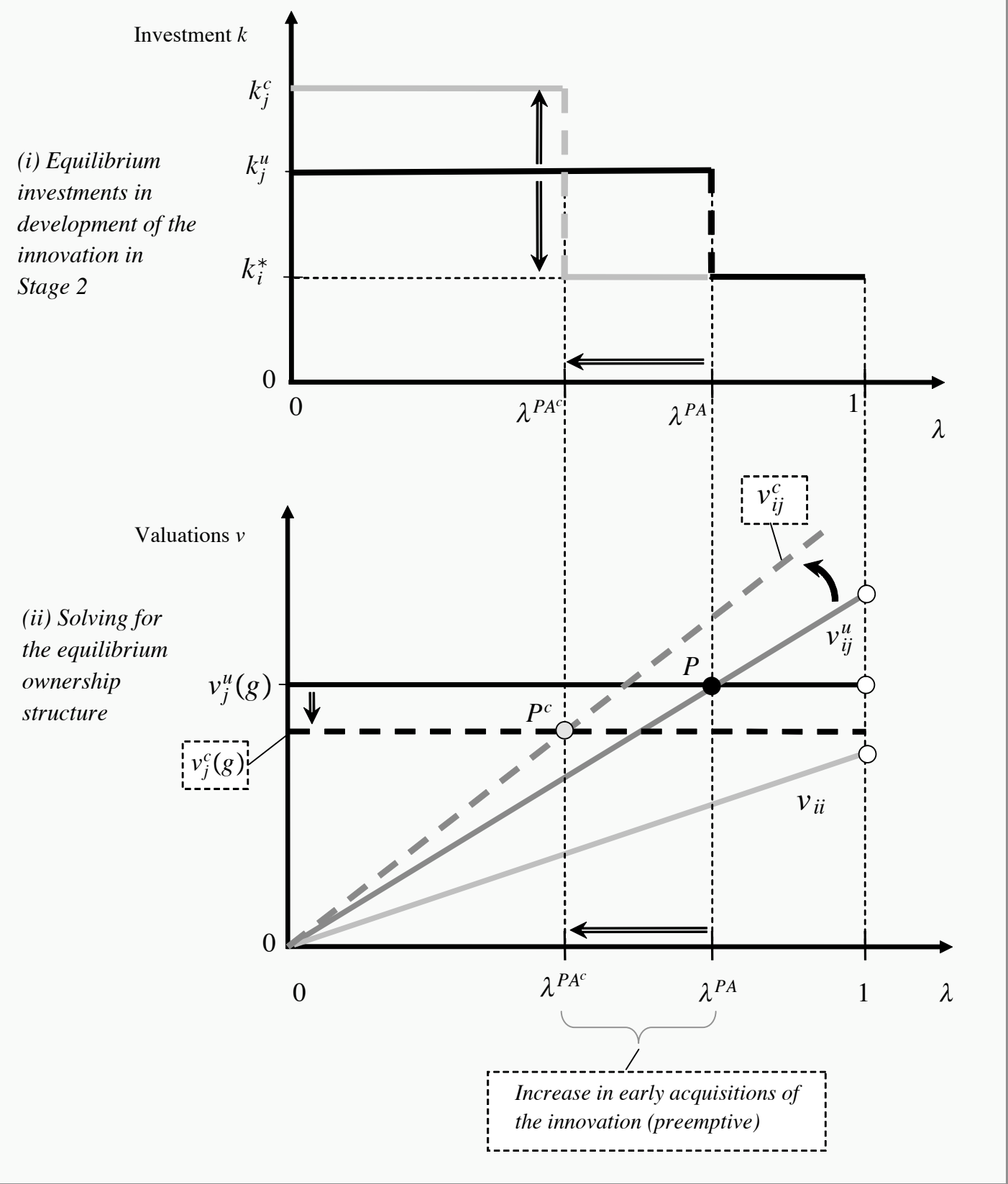

Figure 5: Equilibrium investment and ownership structure with a binding incentive compatibility constraint. 


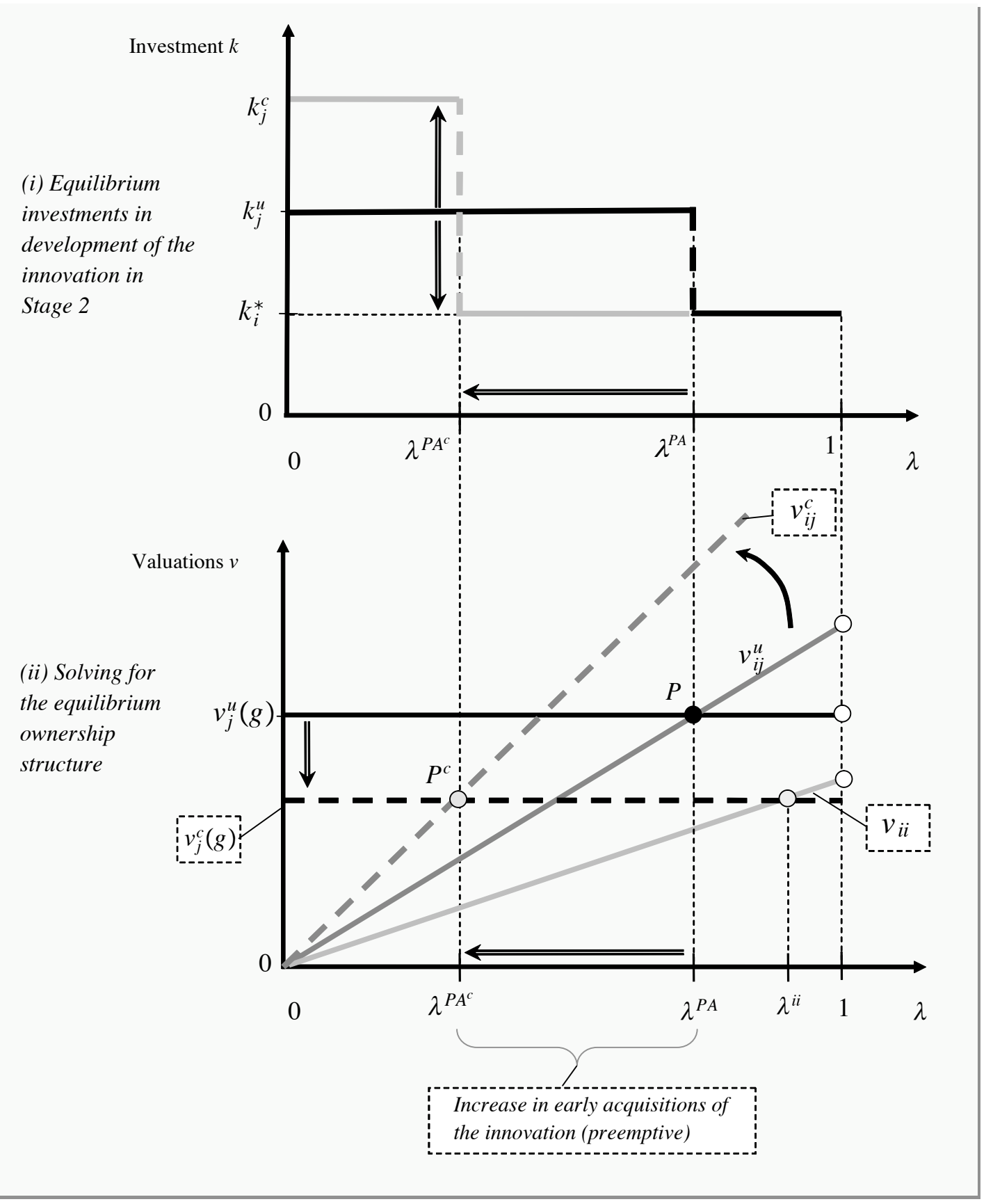

Figure 6: Equilibrium investment and ownership structure with a binding incentive compatibility constraint; for $\lambda>\lambda^{i i}, v_{i i}>v_{j}^{c}(g)$. 
value of obtaining the innovation when it would otherwise be obtained, developed, and sold by a venture-backed firm $j, v_{i j}$.

Let us now compare $v_{i j}$ with $v_{j}(g)$. Denote by $v_{i j}^{c}$ and $v_{i j}^{u}$, respectively, the incumbent's valuation if the venture-backed firm is constrained and unconstrained in its investment choice by the necessity to signal.

Consider first $\lambda \rightarrow 1$ and assume that the venture-backed firm's incentive compatibility constraint is not binding. The valuation for this case, $v_{i j}^{u}$, is shown in Figure 4 (ii). As illustrated by the figure, for $\lambda \rightarrow 1, v_{i j}^{u}>v_{j}^{u}(g)$ : an incumbent is willing to pay more than a venture capitalist to obtain the innovation in order to avoid the overinvestment by the venture capitalist. To see this, consider the difference between these values for $\lambda \rightarrow 1: \lim _{\lambda \rightarrow 1}\left(v_{i j}^{u}-v_{j}^{u}(g)\right)=R_{A}\left(k_{i}^{*}(g) \mid g\right)-C\left(k_{i}^{*}(g)\right)-\left[R_{A}\left(k_{j}^{u}(g)\right)-C\left(k_{j}^{u}(g)\right)\right]$. Since $k_{i}^{*}(g)$ maximizes the acquiring incumbents' net profits $R_{A}(k)-C(k)$, and since $k_{i}^{*}(g) \neq k_{j}^{u}(g)$, this difference must be positive.

Still, consider $\lambda \rightarrow 1$, but now assume that the venture-backed firm's incentive compatibility constraint is binding. In this case, the venture-backed firm must invest $k_{j}^{c}(g)>k_{j}^{u}(g)$ to signal the good nature of the innovation. This reinforces the result that $\lim _{\lambda \rightarrow 1}\left(v_{i j}^{u}-v_{j}^{u}(g)\right)>0$ for two reasons. First, due to the extra investment necessary to signal, the incumbents' outside option in case of a binding incentive compatibility constraint is worse than if the constraint is not binding, $R_{N}\left(k_{j}^{c}(g) \mid g\right)<R_{N}\left(k_{j}^{u}(g) \mid g\right)$, so that $v_{i j}^{c}>v_{i j}^{u}$. Second, as described earlier, this extra investment to signal is costly for the venture-backed firm, thus, $v_{j}^{c}(g)<v_{j}^{u}(g)$. This is illustrated in Figure 5 (ii).

Now consider $\lambda \rightarrow 0$. In this case, irrespective of whether the venture-backed firm's incentive compatibility constraint was binding, $v_{i j}=0<v_{j}(g)$. This is also illustrated in Figure 5 (ii).

As for $\lambda \rightarrow 0, v_{i j}<v_{j}(g)$ and for $\lambda \rightarrow 1, v_{i j}>v_{j}(g)$, and as $v_{i j}-v_{j}(g)$ is continuous and monotonously increasing in $\lambda \in] 0,1[$, there must be a $\lambda \in] 0,1\left[\right.$ for which $v_{i j}=v_{j}(g)$. Denote this $\lambda$ by $\lambda^{P A}$. This notation anticipates that for $\lambda>\lambda^{P A}$ preemptive acquisitions of early stage innovations will occur. We summarize these intermediate results in Lemma 6.

Lemma 6 For all cost functions satisfying assumption $\left.1, \exists \lambda^{P A} \in\right] 0,1\left[\right.$, s.t. for $\lambda>\lambda^{P A}$, $v_{i j}>v_{j}(g)$ and for $\lambda<\lambda^{P A}, v_{i j}<v_{j}(g)$. 
Using Lemmas 5 and 6, we can solve the first-price sealed-bid auction in stage 1 in order to derive the equilibrium ownership of the early stage innovation. Denote the sale price of the early stage (undeveloped) innovation by $S_{1}$.

First, note that bidding competition among the symmetric venture capitalists implies that the equilibrium price of a good innovation cannot be lower than $v_{j}(g)$. Also, note that even though there are several symmetric incumbents bidding for the innovation, they will not bid up to $v_{i j}$. To see this, recall the two purposes of a preemptive acquisition by an incumbent. The first is to avoid another incumbent preemptively acquiring the innovation, the value of which for an incumbent is $v_{i i}$. The second is to avoid a venture capitalist acquiring, overdeveloping, and then selling the innovation at a high sale price, the value of which to an incumbent is $v_{i j}$. We have shown that $v_{i i}<v_{i j}$. Therefore, once one incumbent outbids the venture capitalists (by an $\varepsilon$ ), no other incumbent has an incentive to further outbid this incumbent.

Denoting the equilibrium sale price of the early stage (undeveloped) innovation with $S_{1}^{*}$, it can be shown that the unique Nash equilibrium in that auction entails one of the venture capitalists acquiring a good innovation at a price $S_{1}^{*}=v_{j}(g)$ if $v_{j}(g)>v_{i j}>v_{i i}$; that no one acquires a bad innovation if $v_{j}(g)>v_{i j}>v_{i i}$; that one of the incumbents acquires the early stage innovation at a price $S_{1}^{*}=v_{j}(g)$ if $v_{i j}>v_{j}(g)>v_{i i}$; and that one of the incumbents acquires the early stage innovation at a price $S_{1}^{*}=v_{i i}$ if $v_{i j}>$ $v_{i i}>v_{j}(g)$. The intuition for the fact that there is no one acquiring the bad innovation for $\lambda<\lambda^{P A}$ is the following: Venture capitalists only bid a positive amount for good early stage innovations, and this bid is higher than the expected value of the innovation to the incumbents. Thus, in this interval, incumbents are not able to appropriate good innovations. However, if they were to bid anything positive, they would appropriate the innovation if it is bad. Therefore, they maximize their expected payoff by bidding zero. We can express this result as in proposition 3.

Proposition 3 1. For $\lambda<\lambda^{P A}$ (a) a good innovation will be developed by a venturebacked firm, where the venture capitalist paid a price $S_{1}^{*}=v_{j}(g)$; and (b) a bad innovation will not be acquired by either incumbents or venture capitalists.

2. For $\lambda^{P A}<\lambda<\lambda^{i i}$ (a) a good innovation will be preemptively acquired and developed by an incumbent that paid a price $S_{1}^{*}=v_{j}(g)$; and (b) a bad innovation will be 
preemptively acquired but not developed by an incumbent that paid a price $S_{1}^{*}=$ $v_{j}(g)$;

3. For $\lambda^{i i}<\lambda$ (a) a good innovation will be preemptively acquired and developed by an incumbent that paid a price $S_{1}^{*}=v_{i i}$; and (b) a bad innovation will be preemptively acquired but not developed by an incumbent that paid a price $S_{1}^{*}=v_{i i}$.

Proof. See Appendix C.

Depending on the extent of the venture capitalists' information advantage and their ability to signal which, in turn, depends on the cost difference for developing good and bad innovations, the early stage innovation is either acquired by an incumbent that invests $k_{A}^{*}$ and pays $S_{1}^{*}=v_{j}(g)$ or $S_{1}^{*}=v_{i i}$ or by a venture capitalist that invests $k_{j}^{*}(g)$ and pays $S_{1}^{*}=v_{j}(g)$. This leads to the following corollaries.

Corollary 1 As long as $\lambda$ is sufficiently high, incumbents acquire early stage innovations to preempt, for them, excessive investments in development that would otherwise be undertaken by a venture-backed firm. The threshold level of $\lambda$, for which preemptive acquisitions occur, $\lambda^{P A}$, is smaller the less costly it is for a venture-backed firm to mimic the development of a good innovation when it is bad.

Our results predict when we should expect a vigorous development of good innovations. This is the case whenever venture capitalists are in a position to develop the innovation. Consider panels $(i)$ of figures 4,5 , and 6 . If it is unlikely for an early stage innovation to be good and thus lead to a successfully commercialized innovation after its development, i.e., if $\lambda<\lambda^{P A}$, we observe vigorous development by venture-backed firms. In addition, once we compare the three figures, we can see that the less costly it is for a venture-backed firm to mimic the development of a good idea when it is bad, the more extensively venture-backed firms owning a good innovation will have to develop it in order to signal its good nature.

Corollary 2 (1) Investment in the development of good innovations is vigorous for low $\lambda$ as innovations will then be developed by a venture-backed firm. (2) Investment in the development of good innovations by venture-backed firms is the more vigorous, the cheaper it is for a venture-backed firm possessing a bad innovation to mimic one possessing a good innovation. 


\subsection{Incentives for early stage innovation}

Our results have striking consequences for entrepreneurial incentives to create early stage innovations in the first place. If there were no venture capitalists, entrepreneurs could only turn to incumbents for the development of their early stage innovations. In this case, the incumbents' valuation and winning bid for early stage innovations is, as we have shown, $v_{i i}$. As demonstrated in proposition 3, if entrepreneurs could also turn to venture capitalists, the winning bid might be higher, even in cases where incumbents develop the innovation. These consequences are outlined in this subsection.

If $\lambda<\lambda^{P A}$, the good innovation will be developed by a venture-backed firm. Venture capitalists bid $v_{j}(g)$ in case the innovation is good and zero in case it is bad, while incumbents always bid zero. Consequently, the entrepreneur has a payoff of $v_{j}(g)$ if and only if the early stage innovation turns out to be good and zero otherwise. This leaves him with an expected payoff for the early stage innovation of $\lambda v_{j}(g)$, which we have shown to be greater than $v_{i i}$.

If $\lambda^{P A}<\lambda<\lambda^{i i}$, the early stage innovation will be preemptively acquired by an incumbent, which develops it in case it turns out to be good. The incumbent bids $v_{j}(g)$, which we have also shown to be greater than $v_{i i}$, and the expected payoff for the entrepreneur is $v_{j}(g)$.

If $\lambda^{i i}<\lambda$, once more, the early stage innovation will be preemptively acquired by an incumbent, which develops it in case it turns out to be good. The incumbents bid $v_{i i}$ and the entrepreneur has exactly the same expected payoff in the presence of venture capitalists as it has in their absence.

Therefore, as long as $\lambda<\lambda^{i i}$, the existence of venture capitalists - whether or not they get to develop the innovations - increases the expected payoff from early stage innovations for the entrepreneurs.

Proposition 4 The existence of venture capitalists increases the incentives for entrepreneurs to engage in early stage innovation for $\lambda<\lambda^{i i}$ and does not change them otherwise.

In other words, the existence of venture capitalists may not only generate a more vigorous development of existing early stage innovations, which may result in increased competitiveness in the market, but it may also give higher incentives to entrepreneurs to produce new innovations in the first place. 


\section{Example: Linear-Quadratic Model}

In this section, we give an illustration of our results based on a specific type of competition and specific costs of innovating. We consider a duopolistic market with linear inverse demand $P=a-b X$, where $a>0$ denotes consumers' willingness to pay and $b>0$ denotes market $\operatorname{size}^{21}, P$ is the price of the product, in which ex-ante symmetric incumbents with unit production costs, $c$, compete à la Cournot. The strategic variable in the productmarket interaction (stage 4 ), $x_{i}$, is the quantity chosen by each firm $i$, where $X=\sum_{i=1}^{N_{I}} x_{i}$ is equal to the total industry production. We assume that the development of a good innovation will lead to a unit production cost reduction of $k \in] 0, c[$ units, whereas that of a bad one does not reduce costs, regardless of the level of $k$. Satisfying assumption 1, the cost of development for a venture-backed firm is assumed to be $C_{j}(k \mid \theta)=\frac{\mu_{\theta} k^{2}}{2}$, where $0<\mu_{g}<\mu_{b}<\infty$. The cost of development for an incumbent is assumed to be $C_{i}(k \mid \theta)=\frac{\mu_{g} k^{2}}{2}$.

For the specific assumptions taken in this section, standard Cournot analysis results in $x_{A}^{*}(k \mid g)=\frac{a-c+2 k}{3 b}, x_{N}^{*}(k \mid g)=\frac{a-c-k}{3 b}, R_{A}(k \mid g)=b\left(\frac{a-c+2 k}{3 b}\right)^{2}$, and $R_{N}(k \mid g)=$ $b\left(\frac{a-c-k}{3 b}\right)^{2}$ for a good developed innovation and in $x_{A}^{*}(k \mid b)=x_{N}^{*}(k \mid b)=\frac{a-c}{3 b}$, and $R_{A}(k \mid b)=R_{N}(k \mid b)=b\left(\frac{a-c}{3 b}\right)^{2}$ for a bad innovation. That these reduced-form productmarket profits fulfill assumption 2 is easily verifiable.

Remember that an acquiring incumbent can verify the nature of the innovation after having obtained it and before investing in it. Thus, its optimal investment in the development of a good innovation can be shown to equal $k_{i}^{*}(g)=\frac{4(a-c)}{9 b \mu_{g}-8}$. Similarly, a venturebacked firm's optimal investment in the development of a good innovation, if it is unconstrained and constrained by the necessity to signal, respectively, equal $k_{j}^{u}(g)=\frac{2(a-c)}{3 b \mu_{g}-2}$ and $k_{j}^{c}(g)=\frac{4(a-c)}{3 b \mu_{b}-2}$.

The venture-backed firm's profit from auctioning off the good developed innovation in stage 3 corresponds to its willingness to pay for the early stage innovation, $v_{j}(g)$. It equals $v_{j}^{u}(g)=\frac{2(a-c)^{2}}{3 b\left(3 b \mu_{g}-2\right)}$ for the unconstrained problem and $v_{j}^{c}(g)=\frac{\mu_{b}-\mu_{g}}{2}\left(\frac{4(a-c)}{3 b \mu_{b}-2}\right)^{2}$ for the constrained one. The problem is unconstrained as long as $k_{j}^{u}(g)$ fulfills the venturebacked firm's incentive compatibility constraint, i.e., as long as $S_{3}\left(k_{j}^{u}(g) \mid g\right)-\frac{\mu_{b}\left(k_{j}^{u}(g)\right)^{2}}{2}<$ $0 \Leftrightarrow \frac{1}{b \mu_{b}}<\frac{3}{6 b \mu_{g}-2}$. It can be verified that $v_{j}^{c}(g)=v_{j}^{u}(g)$ if and only if $\frac{1}{b \mu_{b}}=\frac{3}{6 b \mu_{g}-2}$ and

\footnotetext{
${ }^{21}$ The higher $b$, the smaller the market.
} 
$v_{j}^{c}(g)<v_{j}^{u}(g)$ otherwise.

The value for an incumbent firm of acquiring the early stage innovation, when it would otherwise be obtained by a rival incumbent, equals $v_{i i}=\lambda \frac{16(a-c)^{2}\left(b \mu_{g}-1\right)}{b\left(9 b \mu_{g}-8\right)^{2}}$. The value for an incumbent firm of obtaining the innovation when it would otherwise be obtained, developed, and sold by a venture capitalist is $v_{i j}^{u}=\lambda \frac{8(a-c)^{2}}{9 b}\left(\frac{1}{9 b \mu_{g}-8}+\frac{3\left(b \mu_{g}-1\right)}{2\left(3 b \mu_{g}-2\right)^{2}}\right)$ for the unconstrained case and $v_{i j}^{c}=\lambda \frac{8(a-c)^{2}}{9 b}\left(\frac{1}{9 b \mu_{g}-8}+\frac{3 b \mu_{b}-4}{\left(3 b \mu_{b}-2\right)^{2}}\right)$ for the constrained case.

Define $\eta_{g}=\frac{1}{b \mu_{g}}$ as the relative return to development of a good project and $\eta_{b}=\frac{1}{b \mu_{b}}$ as that of a bad project. A high $b$ is equivalent to a small market size and a high $\mu_{\theta}$ to a high cost of development. Therefore, the higher is $\eta_{\theta}=\frac{1}{b \mu_{\theta}}$, the higher is the relative return to development and the more worthwhile is the extra investment in the development of the innovation. Using this transformation, we can represent the equilibrium organization for each $\lambda$ in an $\eta_{g}-\eta_{b}$ graph. We show three of these graphs (for $\lambda=0.3, \lambda=0.6$, and $\lambda=0.9$ ) for a good innovation in figure 7 . As $\eta_{g}>\eta_{b}$ by assumption, given $\mu_{g}<\mu_{b}$, the only region that is economically sensible for our analysis is the one below the diagonal. Note that the closer is a point to the diagonal, the more similar are the costs of developing good and bad innovations.

Our example shows the patterns of the model: Close to the diagonal, where the development costs of good and bad innovations are similar, a venture-backed firm would have to choose a very high investment level in order to signal a good innovation. This would increase its sale price in a late acquisition, and would therefore be more likely to trigger a preemptive acquisition. Furthermore, the higher is $\lambda$, the more preemptive acquisitions will occur.

\section{Discussion of Assumptions}

Will our main findings also hold when we relax some of the assumptions made in the above analysis? In the remaining paragraphs of the paper we discuss (i) the possibility for a venture-backed firm to use not only a productive signal but also a non-productive signal; (ii) the effects of allowing for the exit of a venture-backed firm by an initial public offering; and (iii) some equilibrium selection issues.

(i) Productive versus non-productive signals In our analysis, we have assumed that the venture-backed firm does not use the classic financial signals which are typi- 


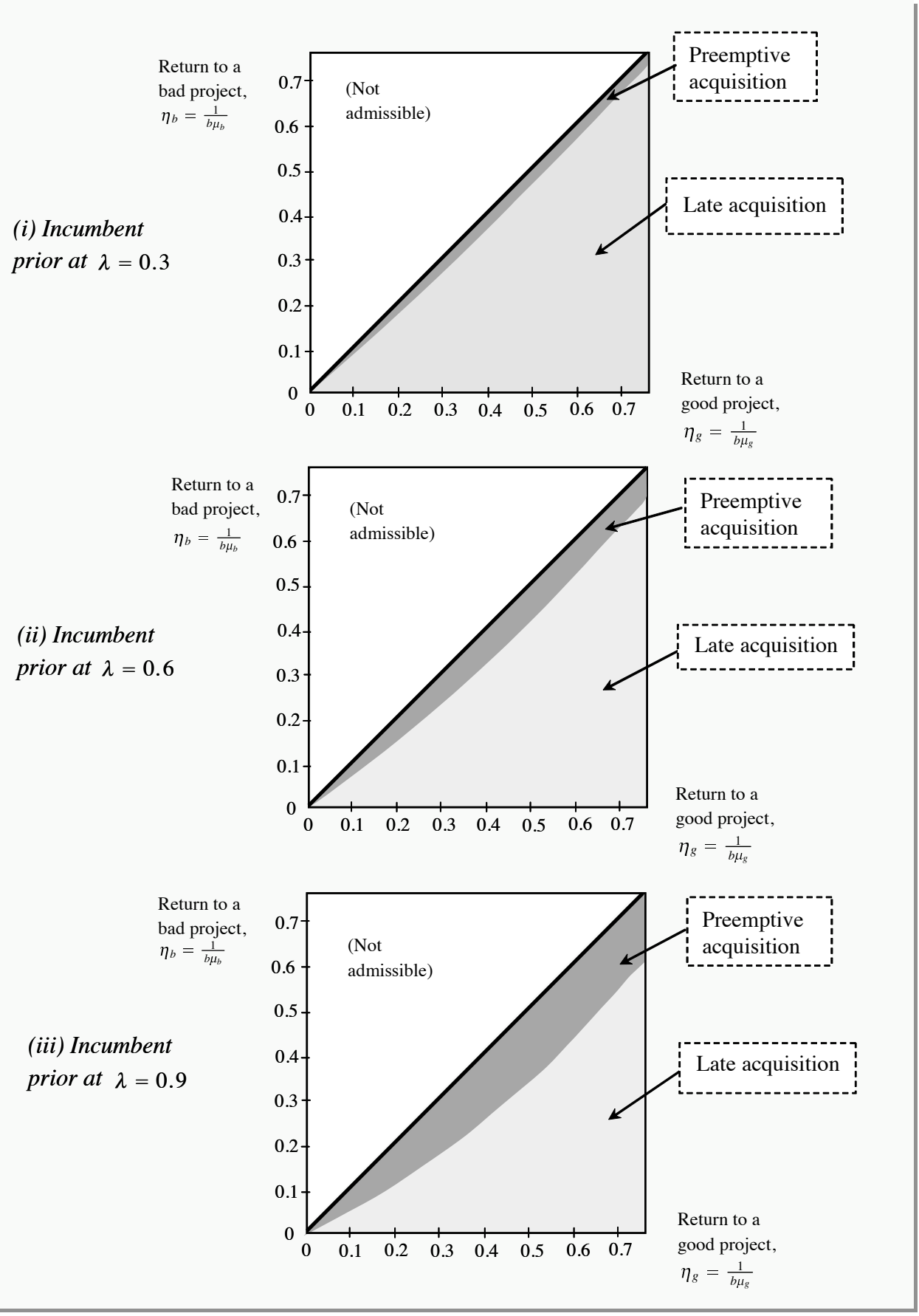

Figure 7: Equilibrium Ownership in the Linear-Quadratic Model; $\eta_{g}$ and $\eta_{b}$ are the relative return to development of good and bad basic innovations, respectively, with $\eta_{g}=1 / \mu_{g} b$ and $\eta_{b}=1 / \mu_{b} b$. 
cally used in initial public offerings (IPOs), including capital structure and underpricing of stocks when selling directly to an incumbent, but rather that the signaling occurs through investment in technology. Indeed, there is evidence that firms in high-tech industries use technology proxies such as the number of $R \& D$ personnel to signal the value of their firms to investors. ${ }^{22}$ There are also studies showing a linkage between $R \& D$ spending and investors' expectations regarding the future value of firms. See for instance [9] Chan, Martin and Kessinger (1990), who find that high-technology firms experience higher abnormal returns than low technology firms when announcements of increased R\&D spending are made, and [13] Doukas and Switzer (1992), who find that firms in high concentration industries experience positive abnormal returns when announcements in $\mathrm{R} \& \mathrm{D}$ are made.

If we allowed for both types of signals, productive and non-productive, then prior to its choice of development, the venture-backed firm would have to consider which signal is more profitable to use. If it is more profitable to use non-productive signals, it will use them and set the investment level equal to the case when no information problem exists. If the cost of signaling or verifying that an innovation is good is the same for the productive and non-productive signals, the venture-backed firm will choose the productive signal. The reason for this choice is twofold: (1) the productive signal will increase the reward (sale price or entry profit) due to the signaling effect; and (2) due to the direct product-market profit effect. On the other hand, non-productive signals only increase the reward due to the signaling effect alone. More generally, the choice between a productive and non-productive signal will depend on what strategies are available and the underlying cost and demand parameters. This choice thus needs to be determined within a specific model. A study of this issue is left to future research.

(ii) Initial public offerings (IPOs) A large part of the existing literature on venture capital concentrates on venture-backed firms that exit by IPOs, whereas we study exit by sale to incumbents. If we allowed both types of exits, i.e., IPOs and sale to incumbents, then the venture-backed firm must, prior to its choice of development (signaling), consider under which conditions it is more profitable to exit, either by IPO or by selling to an incumbent.

\footnotetext{
${ }^{22}$ See [36] Megginson, Wang, and Chua (2001).
} 
Empirically, [17] Gans et al. (2002) and [20] Gans and Stern (2003) show that firms are more likely to act as suppliers of technology to incumbent firms in an M\&A when intellectual property rights are secure, investment costs are high and brokers to facilitate the trade are available. When the opposite applies, start-ups are more likely to commercialize their innovations through entry in an IPO. Furthermore, U.S. data from VentureOne show that, in the last decade, exits through M\&As generated consistently higher aggregate value than exits through IPOs despite the fact that the frequency of M\&As is similar to that of IPOs. This indicates that M\&As are an empirically important exit mode. A comprehensive theoretical study of this issue, however, is beyond the scope of this paper and left to future research. Our model may serve as a basis for such a study.

(iii) Equilibrium selection Signaling games often have multiple equilibria. We have chosen to solve our model for the efficient separating equilibrium in which either the unconstrained profit-maximizing investment, $k_{j}^{u}(g)$, or the minimum necessary investment to signal, $k_{j}^{c}(g)$, is chosen.

However, there also exist pooling equilibria in which venture capitalists choose equal levels of investment in the development of good and bad innovations. In this case, incumbents would not learn the type of the innovation and could bid in stage 3 using only in expectations. Similarly to in the separating equilibrium, in the pooling equilibrium venture-backed firms choose the amount of development in order to maximize the expected difference between the profit of an acquiring and a non-acquiring incumbent. This would increase the sale price an acquirer would have to pay and decrease the profit of non-acquirers as they would face an aggressive rival in the marketplace. In the separating equilibrium, there was an off-setting effect from the transmission of the venture capitalist's superior information to the potential acquirer; with the consequence that incumbents did not prefer to preemptively acquire the early stage innovation if the information advantage of the venture capitalist was sufficiently large. This effect does not exist in a pooling equilibrium and, therefore, incumbents would always acquire preemptively if venture-backed firms were to choose equal investments in the development of good and bad innovations. For this reason we chose not to characterize this equilibrium and instead to concentrate on the more interesting case of the separating equilibrium. 


\section{Concluding remarks}

In this study we have shown that when venture capitalists are specialized in selecting promising early stage innovations they have an incentive to use high investments in the development of an innovation to signal its good nature prior to their exit by selling the innovation to an incumbent. However, we have also shown that incumbents can undertake early preemptive acquisitions to prevent such signaling-driven high investment, despite the risk of buying a bad idea. Consequently, to exist in equilibrium, venture capitalists must be sufficiently more efficient in selecting projects; otherwise preemptive acquisitions by incumbents will take place.

More generally, the paper has shown that the emergence of venture capitalists whose specialty is scrutinizing business plans will not only help the market select projects, but may also create a more vigorous development of innovations in the market and higher rewards for entrepreneurs who find new innovations due to the signaling effect.

\section{References}

[1] Acs, Z. J. and D. B. Audretsch, 2005, "Entrepreneurship, Innovation and Technological Change," Foundations and Trends in Entreprenership, 1, 149-195.

[2] Anton, J. J. and D. A. Yao, 1994, "Expropriation and Inventions: Appropriable rents in the absence of property rights," American Economic Review, 84, 190-209.

[3] Baumol, W. J., 2004, "Entrepreneurial Enterprises, Large Established Firms and Other Components of the Free-Market Growth Machine," Small Business Economics, 23, 9-21.

[4] Ben-Shahar, D., 2004, "Productive Signaling Equilibria and Over-Maintenance: An Application to Real Estate Markets", Journal of Real Estate and Financial Economics, 28, 255-271.

[5] Bianchi, M. and M. Henrekson, 2005, "Is Neoclassical Economics Still Entrepreneurless?", Kyklos, 58, 353-377.

[6] Casamatta, C., 2003, "Financing and Advising: Optimal Financial Contracts with Venture Capitalists," Journal of Finance, 58, 2059-2085. 
[7] Casamatta, C. and C. Haritchabalet, 2007, "Experience, Screening and Syndication in Venture Capital Investments," Journal of Financial Intermediation, 16, 368-398.

[8] Cestone, G., J. Lerner and L. White, 2007. "The Design of Syndicates in Venture Capital," Documento de Trabajo, 7/2006, Fundación BBVA.

[9] Chan, S.H, J.D. Martin, and J.W. Kessinger, 1990, "Corporate Research and Development Expenditures and Share Value," Journal of Accounting and Economics, 26, $255-276$.

[10] Cochrane, J. H., 2005, "The Risk and Return of Venture Capital," Journal of Financial Economics, 75, 3-52.

[11] Cumming, D. J. and S. A. Johan, 2008, "Preplanned exit strategies in venture capital," European Economic Review, 52, 1209-1241.

[12] Cumming, D. J. and J. G. MacIntosh, 2003, "A cross-country comparison of full and partial venture capital exits," Journal of Banking and Finance, 27, 511-548.

[13] Doukas, J. and L. N. Switzer, 1992, "The stock market's view of R\&D spending and market concentration", Journal of Economics and Business, 44, 95-114.

[14] Engel, D., M. Keilbach, 2007, "Firm-level implications of early stage venture capital investment - An empirical investigation," Journal of Empirical Finance, 14, 150-167.

[15] Farrell, J., and C. Shapiro, 1990, "Horizontal Mergers: An Equilibrium Analysis," American Economic Review, 80, 107-126.

[16] Gabszewicz, J.J. and D. Laussel, 2007, "Increasing Returns, Entrepreneurship and Imperfect Competition," Economic Theory, 30, 1-19.

[17] Gans, J.S., D.H. Hsu, and S. Stern, 2002, "When does Start-Up Innovation Spur the Gale of Creative Destruction?," RAND Journal of Economics, 33, 571-586.

[18] Gans, J.S., D.H. Hsu, and S. Stern, 2008, "The Impact of Uncertain Intellectual Property Rights on the Market For Ideas: Evidence From Patent Grant Delays," Management Science, 54, 982-997. 
[19] Gans, J.S. and S. Stern, 2000, "Incumbency and R\&D Incentives: Licensing the Gale of Creative Destruction," Journal of Economics and Management Strategy, 9, $485-511$.

[20] Gans, J.S. and S. Stern, 2003, "The Product Market and the Market for "Ideas": Commercialization Strategies for Technology Entrepreneurs," Research Policy, 32, $333-350$.

[21] Gompers, P. and J. Lerner, 2005, "The Venture Capital Cycle," Cambridge: MIT Press, 2 edn.

[22] Granstrand, O. and S. Sjölander (1990), "The Acquisition of Technology and Small Firms by Large Firms," Journal of Economic Behavior and Organization, 13, 367386.

[23] Hall, B., E. Berndt, and R. Levin, 1990, "The Impact of Corporate Restructuring on Industrial Research and Development," Brookings Papers in Economic Activity, Microeconomics, 1990 (1), 85-136.

[24] Hellmann, T., 2002, "A theory of strategic venture investing," Journal of Financial Economics, 64, 285-314.

[25] Hellmann, T., 2006, "IPOs, Acquisitions and the use of convertible securities in venture capital," Journal of Financial Economics, 81, 649-679.

[26] Hellmann, T. and Puri M., 2000, "The Interaction Between Product Market and Financing Strategy: The role of venture capital," Review of Financial Studies, 13, 959-984.

[27] Inderst, R., and H. Müller, 2004, "The Effect of Capital Market Characteristics on the Value of Start-Up Firms," Journal of Financial Economics, 72, 319-356.

[28] Kamien, M.I., 1992, "Patent Licensing," in Handbook of game theory with economic applications. ed. by R.J. Aumann and S. Hart, vol. 1, chap. 11, pp. 331-354. Elsevier North-Holland: New York, 1 edn.

[29] Kanniainen, V., and C. Keuschnigg, 2003, "The optimal portfolio of start-up firms in venture capital finance," Journal of Corporate Finance, 9, 505-612. 
[30] Kaplan S.N. and P. Stromberg, 2001, "Venture Capitals As Principals: Contracting, Screening, and Monitoring," American Economic Review, 91, 426-430.

[31] Katz, M. L. and C. Shapiro, 1986, "How to licence intangible property," Quarterly Journal of Economics, 101, 567-589.

[32] Keuschnigg, C., and S. B. Nielsen, 2004, "Start-Ups, Venture Capitalists, and the Capital Gains Tax," Journal of Public Economics, 88, 1011-1042.

[33] Keuschnigg, C., and S. B. Nielsen, 2006, "Self-Selection and Advice in Venture Capital Finance," University of St. Gallen Discussion Paper No. 2006-06.

[34] Kortum, S., and J. Lerner, 2000, "Assessing the Contribution of Venture Capital to Innovation," RAND Journal of Economics, 31, 674-692.

[35] Lerner, J. and R. Merges, 1998, "The Control of Strategic Alliances: an Empirical Analysis of the Biotechnology Industry," Journal of Industrial Economics, 46, 125156.

[36] Megginson, W.L., K. Wang, and W. Chua, 2001, "Signal Power of Technological and Financial Variables in Venture Capital," Available at SSRN: http://ssrn.com/abstract=263782, downloaded on 26 June 2008.

[37] Norbäck, P.J., and L. Persson, forthcoming, "The Organization of the Innovation Industry: Entrepreneurs, Venture Capitalists, and Oligopolists," Journal of the European Economic Association.

[38] OECD, 2007, "International Investment Perspectives: Freedom of Investment in a Changing World," OECD, Paris.

[39] Repullo, R. and J. Suarez, 2004, "Venture Capital Finance: A Security Design Approach," Review of Finance, 8, 75-108.

[40] Riley, J.G., 2001, "Silver Signals: Twenty-five years of Signalling and Screening," Journal of Economic Literature, 39, 432-478.

[41] Sahlman, W., 1988, "Aspects of Financial Contracting in Venture Capital," Journal of Applied Corporate Finance, 1, 23-36. 
[42] Sahlman, W., 1990, "The Structure and Governance of Venture-Capital Organizations," Journal of Financial Economics, 27, 473-521.

[43] Schmidt, K., 2003, "Convertible securities and venture capital finance," Journal of Finance, 58, 1139-1166.

\section{Appendix}

\section{A Proof of Lemma 1}

Proof. Denote the equilibrium investment level in a bad project in a separating equilibrium by $k_{j}^{*}(b)$ and that in a good innovation by $k_{j}^{*}(g)$. In any perfect Bayesian equilibrium, beliefs about the equilibrium path must be correctly derived from the equilibrium strategies using Bayes' rule. This implies that observing $k_{j}^{*}(g)$, firms must assign a probability one to the project being good and observing $k_{j}^{*}(b)$, firms must assign a probability one to the project being bad.

Assume first that incumbents observe $k_{j}^{*}(b)$. As $\frac{d R_{h}(k \mid b)}{d k}=0$, the resulting valuation after observing $k_{j}^{*}(b)$ is $w(k \mid b)=R_{A}(k \mid b)-R_{N}(k \mid b)=0$. The resulting maximum (and winning) bid is then $S_{3}=0$.

Assume now that incumbents observe $k_{j}^{*}(g)$. Denote by $b_{i}$ incumbent $i$ 's bid and by $b \in R^{N_{I}}$ the vector of these bids. First, consider the equilibrium candidate where incumbent $\iota \in \mathcal{I}$ acquires the innovation, denoted by a vector $\mathbf{b}^{*}$. Note that $b_{\iota}^{*}>w-\varepsilon$ is a weakly dominated strategy, since no owner will post a bid over its maximum valuation to obtain the innovation. If $b_{\iota}^{*}<w-\varepsilon$, firm $\iota^{\prime}$ benefits from deviating to $b_{\iota^{\prime}}^{* *}=b_{\iota}^{*}+\varepsilon$, since it then obtains the innovation and pays a price lower than its valuation for obtaining it. Last, consider candidate $b_{\iota}^{*}=w-\varepsilon, b_{\iota^{\prime}}^{*}=w-2 \varepsilon$. No owner then has an incentive to deviate. This is therefore a Nash equilibrium and the only NE where firm $\iota$ obtains the assets. Second, note that the situation where no incumbent obtains the innovation cannot occur if there is no reservation price at the auction.

\section{B Proof of Lemma 3}

Proof. Suppose that when the project is bad, the venture-backed firm chooses some strictly positive equilibrium investment level $k_{j}^{\prime}>0$. According to Lemma 1 , it receives 
a payment equal to zero, which it could receive if it chose $k_{j}=0$. Since choosing $k_{j}=0$ saved it the cost of development, the venture-backed firm would be strictly better off by doing so, which contradicts that $k_{j}^{\prime}$ is its equilibrium investment level.

\section{Proof of Proposition 3}

Proof. First note that bidding competition among the symmetric venture capitalists implies that the equilibrium price cannot be lower than $v_{j}$. Moreover, note that no venture capitalist has an incentive to bid higher.

Assume that $\lambda<\lambda^{P A}$. According to Lemma 6, in this case, $v_{i j}<v_{j}$, so that no incumbent would outbid the venture capitalist. In fact, given that in this case a venture capitalist wins if the innovation is good and all venture capitalists bid zero if it is bad, incumbents always bid zero as long as $\lambda<\lambda^{P A}$. This shows part 1 .

Assume that $\lambda^{P A}<\lambda<\lambda^{i i}$. According to Lemma 5 and $6, v_{i i}<v_{j}<v_{i j}$. Let us now consider the equilibrium candidate where one incumbent bids $v_{j}$ and the second highest bid is by a venture capitalist that bids $v_{j}-\varepsilon$. Note that the acquiring incumbent will not deviate to a lower bid since it benefits in expectation from an acquisition at $S_{1}=v_{j}$ by avoiding the excessive investments by venture capitalists, which would otherwise occur in case the innovation turns out to be good. This follows from the acquiring incumbent's net profit being $\pi_{A}^{*}=\lambda\left(R_{A}\left(k_{i}^{*}(g)\right)-C\left(k_{i}^{*}(g)\right)\right)-v_{j}=v_{i j}-v_{j}+\lambda R_{N}\left(k_{j}^{*}(g)\right)>\lambda R_{N}\left(k_{j}^{*}(g)\right)$ by Lemma 6 . Clearly, deviating to a higher bid is not profitable for the winning incumbent. Moreover, other incumbents will not challenge an acquisition by a rival firm since they benefit from weaker market competition, while not bearing the cost of the acquisition. This follows from the fact that $\lambda R_{N}\left(k_{i}^{*}(g)\right)=\lambda\left(R_{A}\left(k_{i}^{*}(g)\right)-C\left(k_{i}^{*}(g)\right)\right)-v_{i i}>$ $\lambda\left(R_{A}\left(k_{i}^{*}(g)\right)-C\left(k_{i}^{*}(g)\right)\right)-v_{j}=\pi_{A}^{*}$ holds by Lemma 6 . This shows part 2.

Assume $\lambda^{i i}<\lambda$. According to Lemma 5 and $6, v_{j}<v_{i i}<v_{i j}$. In this case, bidding competition among the symmetric incumbents implies that the equilibrium price cannot be lower than $S_{1}=v_{i i}$. Moreover, note that no incumbent has an incentive to bid higher. This shows part 3 . 